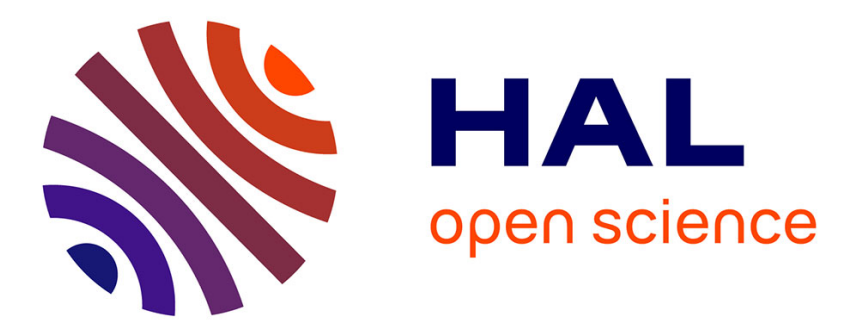

\title{
Accounting for automated identification errors in acoustic surveys
}

Kévin Barré, Isabelle Le Viol, Romain Julliard, Julie Pauwels, Stuart E Newson, Jean-François Julien, Fabien Claireau, Christian Kerbiriou, Yves Bas

\section{> To cite this version:}

Kévin Barré, Isabelle Le Viol, Romain Julliard, Julie Pauwels, Stuart E Newson, et al.. Accounting for automated identification errors in acoustic surveys. Methods in Ecology and Evolution, 2019, 10 (8), pp.1171-1188. 10.1111/2041-210X.13198 . hal-02914597

\section{HAL Id: hal-02914597 https://hal.science/hal-02914597}

Submitted on 12 Aug 2020

HAL is a multi-disciplinary open access archive for the deposit and dissemination of scientific research documents, whether they are published or not. The documents may come from teaching and research institutions in France or abroad, or from public or private research centers.
L'archive ouverte pluridisciplinaire HAL, est destinée au dépôt et à la diffusion de documents scientifiques de niveau recherche, publiés ou non, émanant des établissements d'enseignement et de recherche français ou étrangers, des laboratoires publics ou privés. 


\section{Accounting for automated identification errors in acoustic surveys}

3 Kévin Barré $^{1,2}$, Isabelle Le Viol ${ }^{1,2}$, Romain Julliard ${ }^{1}$, Julie Pauwels ${ }^{1}$, Stuart E. Newson ${ }^{3}$,

4 Jean-François Julien ${ }^{1}$, Fabien Claireau ${ }^{1,4,5}$, Christian Kerbiriou ${ }^{1,2 *}$, Yves Bas ${ }^{1,6^{*}}$

5

$6 \quad{ }^{1}$ Centre d'Ecologie et des Sciences de la Conservation (CESCO), Muséum national d'Histoire 7 naturelle, Centre National de la Recherche Scientifique, Sorbonne Université, CP 135, 57 rue

8 Cuvier, 75005 Paris, France

$9 \quad{ }^{2}$ Centre d'Ecologie et des Sciences de la Conservation (CESCO), Muséum national d'Histoire

10 naturelle, Station de Biologie Marine, 1 place de la Croix, 29900 Concarneau, France

$11{ }^{3}$ British Trust for Ornithology, The Nunnery, Thetford, Norfolk IP24 2PU, UK

$12{ }^{4}$ University of Greifswald, Zoology Institute and Museum, Soldmann-Str. 14, D - 17489

13 Greifswald, Germany.

145 Naturalia Environnement, Site Agroparc, Rue Lawrence Durell, 84911 Avignon, France.

$15{ }^{6}$ Centre d'Ecologie Fonctionnelle et Evolutive (CEFE), UMR 5175, CNRS - Université de

16 Montpellier - Université Paul-Valéry Montpellier - EPHE, 1919 route de Mende, 34293

17 Montpellier, France

$18 *$ Equal contribution as last authors

19

20 Corresponding author:

21 Kévin Barré

22 kevin.barre@edu.mnhn.fr

$23+33298509928$

25 Running title: Accounting for acoustic identification errors 
1. Assessing the state and trend of biodiversity in the face of anthropogenic threats requires large-scale and long-time monitoring, for which new recording methods offer interesting possibilities. Reduced costs and a huge increase in storage capacity of acoustic recorders has resulted in an exponential use of Passive Acoustic Monitoring (PAM) on a wide range of animal groups in recent years. PAM has led to a rapid growth in the quantity of acoustic data, making manual identification increasingly time-consuming. Therefore, software detecting sound events, extracting numerous features, and automatically identifying species have been developed. However, automated identification generates identification errors, which could influence analyses which looks at the ecological response of species. Taking the case of bats for which PAM constitutes an efficient tool, we propose a cautious method to account for errors in acoustic identifications of any taxa without excessive manual checking of recordings. 2. We propose to check a representative sample of the outputs of a software commonly used in acoustic surveys (Tadarida), to model the identification success probability of 10 species and 2 species groups as a function of the confidence score provided for each automated identification. Using this relationship, we then investigated the effect of setting different False Positive Tolerances (FPTs), from a 50\% to $10 \%$ false positive rate, above which data are discarded, by repeating a large-scale analysis of bat response to environmental variables and checking for consistency in the results.

3. Considering estimates, standard errors and significance of species response to environmental variables, the main changes occurred between the naive (i.e. raw data) and robust analyses (i.e. using FPTs). Responses were highly stable between FPTs.

4. We conclude it was essential to, at least, remove data above 50\% FPT to minimize false positives. We recommend systematically checking the consistency of responses for at least 
51 conclusive interpretation when these are consistent. This study provides a huge saving of time

52 for manual checking, which will facilitate the improvement of large-scale monitoring, and 53 ultimately our understanding of ecological responses.

54

55 Key words: bioacoustic, cautious threshold, Chiroptera, error rate, false-positives, Passive 56 Acoustic Monitoring, semi-automated identification, survey methods 
With few exceptions, the rate of biodiversity loss does not appear to be slowing down (Butchart et al., 2010). In 2010, the 10th Conference of Parties to the Convention on Biological Diversity adopted a new 2011-2020 global Strategic Plan for Biodiversity, and in turn, the European Union launched a new Biodiversity Strategy (2011/2307). This strategy aims to halt biodiversity loss and the degradation of ecosystem services by 2020 . Such objectives require large-scale and long-time studies using adapted monitoring methods for surveying and understanding biodiversity changes (Fisher, Frank, \& Leggett, 2010) in response to anthropogenic pressures and environmental policies. The implementation of such studies is highly constrained by the time and cost induced. Interestingly, the development of new recording methods, such as Passive Acoustic Monitoring (PAM), offers interesting possibilities and are taking an increasing place in monitoring (Gibb, Browning, GloverKapfer, \& Jones, 2018).

The reduced costs of acoustic recorders and the huge increase in storage capacity has resulted in an exponential increase in the use of PAM on a very wide range of species groups within a few years (e.g. Stahlschmidt \& Brühl, 2012; Froidevaux, Zellweger, Bollmann, \& Obrist, 2014; Kalan et al., 2015; Jeliazkov et al., 2016; Nowacek, Christiansen, Bejder, Goldbogen, \& Friedlaender, 2016; Frommolt, 2017). Such approaches are already widely used by researchers as well as by people working for environmental consultancies and government agencies for various biodiversity evaluation (Adams, Jantzen, Hamilton, \& Fenton, 2012). PAM can be particularly useful to carry out surveys on cryptic taxa such as nocturnal fauna (Delport, Kemp, \& Ferguson, 2002; Newson, Evans, \& Gillings, 2015; Jeliazkov et al., 2016),

81 and to monitor pristine habitats which are otherwise difficult to access and survey by other approaches (Gasc, Sueur, Pavoine, Pellens, \& Grandcolas, 2013). PAM is also mobilized in 
citizen science programs, for which it is an efficient tool for the implementation of large-scale biodiversity monitoring (Newson et al., 2015; Jeliazkov et al., 2016; Kerbiriou, Azam, et al., 2018; Penone, Kerbiriou, Julien, Marmet, \& Le Viol, 2018).

Despite rapid and exciting developments in acoustic monitoring, there have been substantial challenges in developing this technology into a cost-effective, scalable monitoring tool.

Perhaps the biggest and most complex issue facing acoustic monitoring has been the objective and statistical taxonomic identification of bioacoustic signals. With the arrival on the market of a new generation of affordable acoustic recorders, which allow for continuous recordings over several days, such volumes of acoustic data cannot be processed manually (Newson et al., 2015; Bas, Bas, \& Julien, 2017).

In parallel to the development of PAM, several methods for detecting sound events, extracting numerous features, and automatically identifying species have been developed (Parsons \& Jones, 2000; Britzke, Duchamp, Murray, Swihart, \& Robbins, 2011; Adams et al., 2012; Bas et al., 2017; Ovaskainen, Moliterno de Camargo, \& Somervuo, 2018). However, automated identification software have been criticised due to significant error rates, suggesting cautious and limited use (Russo \& Voigt, 2016; Rydell, Nyman, Eklöf, Jones, \& Russo, 2017), which heavily reduces the advantages of automated algorithms. Nonetheless, authors have highlighted the potential for combining automated classifiers with manual validation to help overcome error risks associated with automated identification, and so saving a huge amount of work in reducing the extent of manual checking required (López-Baucells et al., 2019). Moreover, most available software provides confidence scores associated with each automated identification in the form of probabilities or other numerical indexes (Obrist, Boesch, \& Fluckiger, 2004; Waters \& Barlow, 2013), which unlike the error rate is not dependent of the relative abundance of the species. The confidence scores provided by software aim to be an indicator of the true success probabilities of automated identifications, 
108 and are strongly species-dependant. There is thus an implicit relationship between the error

109 rate and confidence scores and most software manuals advocate using confidence thresholds

110 below which data should be discarded to minimise the error rate, e.g. Tadarida (Bas et al.,

111 2017), SonoChiro (Biotope, 2013) and BatClassify (Scott \& Altringham, 2017). Regardless of

112 the software used, the relationship between the error rate and confidence scores is an

113 important part of the automated identification performance, yet it has never been directly

114 assessed in previous methodological studies (Fritsch \& Bruckner 2014; Rydell et al. 2017).

115 Consequently, the level at which confidence thresholds should be set is unclear to most users,

116 which has limited the use of automated identification in ecological studies. A threshold that is

117 too cautious could lead to high generated false negative rates (i.e. by discarding a large

118 proportion of data containing true positives below a given confidence score), which could

119 result in a lack of statistical power. In contrast, a threshold that is not cautious enough could

120 lead to high false positive rates (i.e. fails in automated identifications), particularly through

121 the inclusion of records of species which are most similar acoustically, which involve

122 statistical noise. Moreover, errors (generated false negative rates or false positive rates) could

123 also be spatially clustered by environmental conditions that alter the quality of the signal

124 (Denzinger \& Schnitzler, 2013), which potentially induce statistical biases in relation with

125 confidence measure provided by the software. False positive rates and generated false

126 negative rates thus induce different caveats for which there is not a unique way to set

127 confidence thresholds. Given the wide range of taxa for which PAM is increasingly being

128 used, there is a need to account for these caveats using a method generalizable to any

129 acoustically surveyed taxa.

130 In this study we propose a method for assessing the effect of using confidence thresholds in

131 acoustic automated identification on the detection of species responses to environmental

132 variables. This method can be applied to any acoustic taxa for which automated identification 
133 software and acoustic signature knowledges are already developed, and where confidence

134 scores are provided. Taking the case of bats, we first manually checked a representative

135 sample of a large number of bat recordings identified using an automated identification

136 software (Tadarida; Bas et al., 2017) commonly used in bat studies (Barré, Le Viol, Julliard,

137 Chiron, \& Kerbiriou, 2017; Barré, Le Viol, Bas, Julliard, \& Kerbiriou, 2018; Claireau et al.,

138 2018; Pinaud, Claireau, Leuchtmann, \& Kerbiriou, 2018; Pauwels et al., 2019). Using this

139 sample, we then modelled the identification success for 10 species and 2 species groups of

140 bats in relation to the confidence score provided by the software. This allowed us to define the

141 minimum confidence score needed to ensure a given False Positive Tolerance (FPT). We then

142 examined how setting different FPTs, from 50\% to $10 \%$ maximum false positive rate, above

143 which data are discarded, may affect a statistical inference by repeating a large-scale analysis

144 of the response of species and species groups activity to five environmental variables, and

145 looking at consistency of the results among FPTs.

146 


\section{Bat survey}

150 We used an acoustic dataset collected previously to study the effect of wind turbines on bat

151 activity (Barré et al., 2018) because it was based on a random sampling design with high

152 variability and no confounding effects in terms of environmental variables (Fig. S1). The

153 following environmental variables are known as good predictors of bat activity: type of site

154 i.e., hedgerow $v s$. open area habitat located at an average of $86 \mathrm{~m}$ (Standard Deviation: $70 \mathrm{~m}$ )

155 away from any hedgerow (Verboom \& Huitema, 1997; Lacoeuilhe, Machon, Julien, \&

156 Kerbiriou, 2016), the distance in meters to a forest (mean=700, SD=506; Boughey et al. 2011;

157 Frey-Ehrenbold et al. 2013), the distance to an urban area (mean=335, SD=170; Azam et al.

158 2016), the distance to a wetland (mean $=579, \mathrm{SD}=363$; Sirami et al. 2013; Santos et al. 2013)

159 and the total length of hedgerows in meters within a 1000 m radius (mean=3439, $\mathrm{SD}=1622$;

160 Verboom \& Huitema, 1997; Lacoeuilhe et al., 2016). The latter four variables presented

161 important environmental variability, and a similar gradient between sites located close to

162 hedgerows and those in open areas (Fig. S1).

163 Bats were recorded at 337 sites (one complete night per site, with 207 sites close to

164 hedgerows and 130 sites in open area) in northwest France (Fig. 1) dominated by agriculture

$165(82 \%)$ and forest (11\%) areas. Recordings were carried out over 23 complete nights, recording

166 from 30 minutes before sunset until 30 minutes after sunrise, from the $7^{\text {th }}$ of September to the

$1678^{\text {th }}$ of October 2016.

168 We simultaneously sampled 11-15 survey sites per night separated by at least $300 \mathrm{~m}$ (Fig.1).

169 Echolocation calls were recorded using one automatic acoustic recorder per site survey (Song

170 Meter SM2Bat+, Wildlife Acoustics Inc., Concord, MA, USA). The detectors automatically

171 recorded all ultrasounds using predefined settings as recommended by the French bat 
monitoring program "Vigie-Chiro" (trigger level set to $6 \mathrm{~dB}$ Signal Noise Ratio and set to continue recording until 2.0 seconds after last trigger event, $384 \mathrm{kHz}$ sampling rate; for further details see Azam et al., 2018; Barré et al., 2018; Claireau et al., 2018; Pauwels et al., 2019). Whilst continuous recording is typically used for monitoring birds and several other species groups, for bats which echolocate at high frequency, and so produce heavy sound files, it is necessary to use triggered recording, to be able to manage and store the data and process the recordings. In addition, these trigger settings are very sensitive $(6 \mathrm{~dB}$ of signal-tonoise ratio) and detect the majority of bats which would have been detected if recording were continuous. As recommended by Millon et al. (2015) and Kerbiriou et al. (2018), we retained one bat pass per five-second interval, which is the mean duration of all bat species passes.

\section{Step 1: manual checking of a subset of the data}

The identification process performed in the first step was divided in two sub-steps (Fig. 1). In the first sub-step, echolocation calls were detected and classified to the closest taxonomic level using the Tadarida software (Bas et al., 2017) (hereafter named primary identification), which assigns a species and confidence score (continuous values between 0 and 1 ) to each recorded bat pass (212 347 in total). In the second sub-step, we selected a representative sample by a stratified random sampling of 25 primary identifications for each 0.1 class of confidence score (i.e. 10 classes in total) for each species and groups for manual checking, except for Rhinolophus species for which all identifications were selected due to their low number. We performed a double manual checking (KB and $\mathrm{YB})$ on this stratified random selection of 1910 bat passes (hereafter names checked dataset or manual checking), using BatSound $\odot$ software (Pettersson Elektronik AB, Sweden) and Syrinx software (John Burt, Seattle, WA, USA) for 10 species and two groups (Myotis spp. and Plecotus spp.) (Table 1), by visual inspection and measurement of discriminating characteristics of calls on 
197 spectrograms (Barataud, 2015). Species groups were used for genera within which species are 198 difficult to identify from one another, except for one species of Myotis spp., Myotis nattereri, 199 for which echolocation calls are very characteristic (Obrist et al., 2004; Barataud, 2015). We 200 made the choice to separate two species which are commonly grouped because of their 201 frequency overlap: Pipistrellus kuhlii and Pipistrellus nathusii. We manually separated these 202 species by combining measurements of energy peak, final frequency, call duration, bandwidth 203 and time between calls as discussed in Barataud (2015). In relatively open habitats like in our 204 study, $P$. nathusii emit very commonly very short bandwidth, and higher frequencies than $P$. $205 k u h l i i$ when emitting such kind of calls (i.e. quasi-constant frequency). P. kuhlii very often use 206 a short frequency modulation at the end of the call and this is very rare in $P$. nathusii calls.

207 Finally, we randomly checked 500 sound files identified as not containing bats to assess 208 missed bat events.

209 We assumed that manual checking provided the most conservative species assignations, 210 which allowed us to accurately assign to each primary identification a true positive (i.e. a 211 correct automated identification of the species), a false positive (i.e. a fail in automated 212 identification of the species) or a false negative (i.e. defined in this study as a pass of the 213 species automatically identified as another one) in the checked dataset.

214 The efficiency of the automated identification may be spatially heterogeneous due to habitat 215 structure (Denzinger \& Schnitzler, 2013). We tested for the dependence of false positives (i.e. 216 a binomial response variable: failure or success of the automated identification) and false 217 negative ones (i.e. a binomial response variable: automatically identified as another species or 218 correct identification) on the five tested environmental variables. We performed generalized 219 linear mixed models (binomial response variables; logit link) with the environmental variables as explanatory variables, using date as random effect to control for inter-night variations. 
223 The success probability, defined as the success or failure of the automated species

224 identification, was used as the response variable to perform generalized linear models

225 (binomial response variable; logit link) using the confidence score provided by the automated 226 identification software as the explanatory variable (see step 2 in Fig.1; Fig. 2). Using these 227 models, we could predict the confidence score corresponding to a given success probability of 228 the automated identification. Thus, predicted confidence score constitutes the minimum one 229 required to ensure a given False Positive Tolerance (FPT, i.e. one minus the success 230 probability) in the whole dataset (i.e. including all checked and non-checked primary 231 identifications; Fig.1; Table 2). We selected all FPTs starting from the highest acceptable one 232 (0.5, i.e. a maximum false positive rate of $50 \%$, which expected to give an approximately 233 balanced number of false negatives and false positives) to the lower one (0.1, i.e. a maximum 234 false positive rate of $10 \%$ ) by 0.1 classes (i.e. $0.5,0.4,0.3,0.2$ and 0.1 FPTs).

Step 3: data thresholding and consistency of model outputs regarding false positive rate

237 After predicting the required confidence score to ensure a given FPT in the automated 238 identification, we filtered the whole dataset on the five predicted confidence scores 239 corresponding to the five FPT (see step 3 in Fig.1; Fig. 3; Table 2). This allowed us to 240 calculate for each FPT in the whole dataset, the remaining number of bat passes, occurrences, 241 and an estimation of false positive rate and generated false negative rate by reducing the FPT 242 (Table 2). In order to assess the trade-off between false positive rates and generated false 243 negative rates generated by reducing FPT, for each FPT, we estimated for the whole dataset 244 the false positive rate (i.e. incorrect primary identifications) and generated false negative rate 245 (i.e. as a consequence of discarding true positives because of reducing FPT) from equations 246 used to model the false positive rate in step 2. For each bat pass $B P$ of a given species $S$, we 
247 first computed the probability of there being a true positive (TP, equation 1) and a false

248 positive (FP, equation 2) as follows:

$$
\mathrm{TP}_{B P, S}=\frac{\exp (a x+b)}{1+\exp (a x+b)}
$$

$$
\mathrm{FP}_{B P, S}=1-\mathrm{TP}_{B P, S}
$$

252 where $a$ corresponds to the estimated parameter from the logistic regression between manual 253 checking (i.e. the response variable: success/fail in automated identification; step 2 in Fig. 1, 254 Fig. 2) with the confidence score provided by the software (i.e. the explanatory variable), $x$ is 255 the confidence score of the bat pass provided by the automated identification software and $b$ is 256 the intercept of the logistic regression (Fig. S2).

257 This allowed us to estimate the generated false negative rate (FNR, equation 3 ) for a given 258 species $S$ and a given threshold of false positive tolerance FPT in the whole dataset, by averaging all probabilities to have a true positive TP from bat passes $B P$ discarded by reducing FPT (i.e. between the targeted FPT and the maximum FPT of 1) as follows:

$$
\mathrm{FNR}_{S, F P T}=\frac{\sum_{F P T}^{F P T=1} \mathrm{TP}_{B P, S}}{n_{B P, S}}
$$

262 where $n$ is the total number of bat passes $B P$ of the species $S$.

263 We were also able to estimate the false positive rate (FPR, equation 4) for a given species $S$ 264 and a given threshold of false positive tolerance FPT in the whole dataset, by averaging 265 probabilities to have a false positive FP from bat passes $B P$ between the minimum FPT (i.e. 266 zero) and the targeted FPT as follows:

$$
\mathrm{FPR}_{S, F P T}=\frac{\sum_{F P T=0}^{F P T} \mathrm{FP}_{B P, S}}{n_{B P, S F P T}}
$$

268 where $n$ is the number of bat passes $B P$ between the minimum FPT (i.e. zero tolerance of false positives) and the targeted FPT of a given species $S$. 
270 Finally, we evaluated the automated classification efficiency by drawing Receiver Operating

271 Characteristic (ROC) curves between confidence scores of presences and absences of each 272 species, and computing Area Under Curve (AUC) with the R package PRROC (Fig. S3).

273 For each species and species groups, we then performed Generalized Linear Mixed Models

274 (GLMM, R package lme4) using as a response variable the number of bat passes filtered on 275 one of the five FPTs or the raw number of primary identifications without thresholding (i.e.

276 whole dataset) (six GLMMs in total performed on 0.5,0.4, 0.3, 0.2, 0.1 FPTs and on the whole 277 dataset). Environmental variables were included as fixed effects, among which quantitative 278 ones were scaled. According to the sampling design (i.e. 11-15 simultaneous recording sites 279 per night), we included date as a random effect to control for inter-night variation in weather 280 conditions and landscape context. We applied a Poisson error or a Negative binomial error 281 distribution to GLMMs in order to minimize issues in the overdispersion ratio in models (i.e. 282 as close as possible to 1; Zuur, Ieno, Walker, Saveliev, \& Smith, 2009). All explanatory 283 variables showed a Variance Inflation Factor value under 1.5, meaning there was no strong 284 evidence of multicollinearity (Chatterjee \& Hadi, 2006).

285 We then compared the estimates of each environmental variable among fitted models to check 286 the consistency in the response of bats to environmental variables in relation to the different 287 FPTs. 


\section{Results}

Automated identification and manual checking

292 Over the 23 nights sampled, among the 212347 bat passes recorded, 167504 (79\%) were

293

294

295

296

297 assigned to Pipistrellus pipistrellus, 28589 (13\%) to Pipistrellus kuhlii, 6430 (3\%) to Myotis spp. and 5835 (3\%) to Barbastella barbastellus (Table 1). A stratified random sample of 1910 bat passes were manually checked (Table 1). False positive rates varied a lot among species, from $0.0 \%$ for Rhinolophus ferrumequinum to $69.4 \%$ for Nyctalus noctula (Table 1). The largest number of errors detected in manual checks was for $N$. noctula confused with social calls of $P$. pipistrellus (only one location involved) and non-bat noises, and. calls of Pipistrellus nathusii were confused with P. kuhlii, P. pipistrellus and non-bat noises (Table S1). Concerning the random checking of 500 sound files identified as non-bat by the software, we found that three $(0.6 \%)$ contained bat events.

\section{Checking for environmental biases in identification errors}

Using the dataset on which manual checks were carried out, we investigated a potential variation in automated identification errors due the environmental variables. The probability of these being false positives was significantly affected by only one environmental variable (habitat type of survey sites: hedgerow vs. open area) and for one species only, N. noctula (P $<0.001$; Table S2). All other environmental variables were not found to affect the probability of there being false negatives for any species (Table S3).

\section{False positive rate modelling}

Success and failure in automated identification assessed through manual checking were modelled in relation to the confidence score provided by the software, allowing us to predict 
314 the required confidence score to ensure a given FPT (Fig. 2). Confidence scores required to

315 ensure FPTs (i.e. 0.5, 0.4, 0.3, 0.2 and 0.1 ) did not vary much for species such as $B$.

316 barbastellus (0.12-0.20), Eptesicus serotinus (0.18-0.29) and Rhinolophus hipposideros (0.39-

317 0.45), but more for others, e.g. Nyctalus leisleri (0.29-0.59), P. kuhlii (0.16-0.44) and Plecotus

318 ssp. (0.18-0.36) (Table 2). In addition, these FPTs confidence scores were low for $B$.

319 barbastellus, E. serotinus, P. kuhlii, Plecotus spp., Myotis spp., and higher for P. nathusii and 320 N. noctula (Table 2).

321 For $P$. pipistrellus errors were rare thus the lowest possible confidence score (0.096)

322 corresponded to a FPT lower than 0.2. In contrast, for P. nathusii, the highest possible

323 confidence score $(0.971)$ corresponded to a FPT greater than 0.1, i.e. more than one in ten

324 chance of failure (Table 2). Moreover, no errors were found in the sample for $R$.

325 ferrumequinum, which prevented the modelling of error rate for this species (Table 2).

326 Low FPTs (i.e. removing data below a high confidence score) often led to an important

327 decrease in activity measures (Table 2). For example, Myotis spp. and N. leisleri activity

328 decreased by $27.8 \%$ and $82.1 \%$, respectively, between 0.5 FPT and 0.1 FPT (Table 2).

329 However, such high decreases in activity resulted in a little decrease in occurrence for these

330 species: $6.7 \%$ for the Myotis spp. group and $10.7 \%$ for $N$. leisleri (Table 2). For other species,

331 the activity and occurrence were more stable across FPTs, including for B. barbastellus, E.

332 serotinus, P. kuhlii, Plecotus spp. and R. hipposideros (Table 2).

333 At the highest FPT (0.5), the estimated false positive rate was high (>21\%) for three species

334 (N. leisleri, N. noctula and P. nathusii), and very low (<5\%) for six species (B. barbastellus,

335 E. serotinus, $P$. kuhlii, P. pipistrellus, $R$. ferrumequinum and $R$. hipposideros) (Table 2).

336 However, at the lowest FPT (0.1), all species showed an estimated false positive rate under

337 0.05, except for $N$. leisleri (0.08) and P. nathusii for which no data satisfied a FPT lower than

3380.1 (Table 2). 
339 Estimating the generated false negative rate (i.e. true positives discarded by reducing the FPT)

340 was very low $(<4 \%)$ at 0.5 FPT for most species except $N$. leisleri $(0.19)$ and P. nathusii

341 (0.28) (Table 2). This rate became more important at 0.1 FPT, with null values for $P$.

342 pipistrellus and $R$. ferrumequinum; with very low values $(<10 \%)$ for five species $(B$.

343 barbastellus, E. serotinus, N. noctula, $P$. kuhlii, and $R$. hipposideros); and with high values

344 for $N$. leisleri (0.425) and P. nathusii (0.377) (Table 2). The average AUC from ROC curves

345 was 0.93 (range: 0.73-1.00; Fig. S3).

\section{Consistency of activity patterns across error rate tolerance gradient}

348 To study the influence of confidence score thresholding according to FPTs below which data

349 were discarded (i.e. changes in amount of data, species occurrence, estimated false positive

350 rate and estimated rate of generated false negative), modelling of the bat response (i.e. the

351 number of bat passes according to selected FPT) to environmental variables was performed at 352 all FPTs.

353 When comparing model outputs from naive (i.e. raw data) to robust analyses (i.e. FPTs), a

354 loss or a gain of significance occurred for the open areas $v s$. hedgerows variable for $N$.

355 leisleri, the distance to forest for Myotis spp. and N. leisleri, the length of hedgerows for $N$.

356 leisleri and the distance to urban areas for $N$. noctula (Table 3). In addition, for significant

357 variables, an inversion of the direction of the estimate for the open areas vs. hedgerows

358 variable occurred for $N$. noctula and P. nathusii (Table 3). In all other cases, no changes were 359 found (Table 3).

360 However, we did not detect any major changes in model outputs between the $0.5,0.4,0.3,0.2$ 361 and 0.1 FPTs for which response estimates and standard errors remained highly stable (Table

362 3). In only two cases, we detected a loss of significance: for $N$. noctula with FPTs lower than 3630.2 and 0.3 for the distance to forests and the length of hedgerows variables, respectively 
364 (Table 3). However, for this species, the open areas vs. hedgerows variable remained 365 significant and highly stable at all FPTs (Table 3).

366 All species had at least one significant habitat variable response irrespective of the used FPTs, 367 except $N$. leisleri. Hedgerows had a significantly higher bat activity (i.e. number of bat 368 passes) associated with them than open areas for seven species or groups (B. barbastellus, $M$. 369 nattereri, Myotis spp., P. kuhlii, P. pipistrellus, Plecotus spp. and R. hipposideros) and a 370 significantly lower bat activity for two species (N. noctula and P. nathusii) (Table 3). We also 371 found a significant negative relationship between bat activity and i) the distance to urban 372 areas variable for two species or groups (E. serotinus and Plecotus spp.; Table 3); ii) with the 373 distance to forest variable for two species (N. noctula and R. ferrumequinum; Table 3); iii)

374 with the distance to wetlands variable for R. ferrumequinum; and iv) with the length of 375 hedgerows variable for $N$. noctula, P. pipistrellus and $R$. ferrumequinum (Table 3) but a 376 significant positive relationship with the distance to wetlands variable for $P$. kuhlii (Table 3). 


\section{Discussion}

380 This study demonstrates that automated acoustic identification of bats, as well as by extension 381 all other taxa acoustically identifiable by software, coupled with partial manual checking and 382 false positive rate modelling (i.e. semi-automated identification; Newson et al. 2015), is a key 383 tool for improving reliability of studies based on acoustic data. Indeed, robust ecological 384 responses could be produced even in cases where false positive rates were so far considered 385 too high (Rydell et al. 2017). This new and robust framework takes advantage of confidence 386 scores provided by the automated identification software and its ability for distinguishing true 387 positives and false positives (Fig. S3), controlling for False Positive Tolerances (FPTs), and 388 checking for potential biases induced by identification errors.

Using confidence thresholding

391 Minimum confidence scores required to ensure a given FPT according to species exhibited 392 low to moderate variation across the 0.5 to 0.1 FPTs (Table 2). To investigate the effect of the 393 automated identification errors on bat activity patterns in relation with FPTs, we studied the 394 response of bat activity to several environmental variables known to impact bats. Depending on species, the most significant responses to environmental variables were consistent with

396 known patterns of bat activity: a negative effect of open areas $v s$. hedgerows and of 397 decreasing length of hedgerows (Verboom \& Huitema, 1997; Lacoeuilhe et al., 2016), of 398 distance to forest (Boughey et al., 2011; Frey-Ehrenbold et al., 2013), to urban areas 399 (Mckinney, 2005; Jung \& Threlfall, 2016) and to distance to wetlands (Santos et al., 2013; 400 Sirami et al., 2013).

401 A comparison of the relationship between environmental variables and bat activity between 402 using the raw data (i.e. using the whole dataset regardless of the confidence score) and FPTs - 
403

selected data (i.e. removing data above defined FPT to minimize the false positive rate)

404 showed some discrepancies. We sometimes found opposite significant responses, for example 405 the effect of open areas $v s$. hedgerows on $N$. noctula and P. nathusii, when comparing results from raw data and FPTs (Table 3). This demonstrates that analyses conducted on raw automated identification data could be severely biased. In this respect, removing data above a 0.5 FPT (i.e. removing data with a low success probability) is essential, in accordance with concerns expressed by Russo \& Voigt (2016).

Logically these biases due to false positives mostly seem to impact uncommon species which are acoustically similar to commoner ones. Here the most impacted species is $P$. nathusii which suffers from a high false positive rate due to the local abundance of $P$. kuhlii and $P$. pipistrellus (Tables 1 \& 2). Consequently, an analysis conducted on raw automatically identified data for this species seems to be driven by the response of the two other Pipistrelles.

\section{Assessing robustness of ecological inferences}

We assessed the robustness of ecological inferences by studying the consistency of bat responses to environmental variables among FPTs. However, for $P$. nathusii it was not possible to ensure such a robustness due a lack of data from 0.4 FPT (Table 2). This framework thus showed that this was not possible to produce robust ecological inferences on this species due to a high false positive rate in this dataset. In addition, for $N$. noctula, we lost significance of the response to the distance to the forest and the length of hedgerows from 0.2 and 0.3 FPTs respectively (Table 3). Such loss of significance could be linked to a high loss of bat passes and occurrences by reducing the FPTs, or linked to environmental biases affecting spatial distribution of false positive or generated false negative rates. Thus, given the uncertainty about the mechanism involved, it was also not possible to produce robust 
inferences for this species given high losses of bat passes and occurrence, and high estimated

428 false positive rates by reducing the FPTs (Table 2).

429 At the other end of the spectrum, the estimated false positive rate was always extremely low 430 or even zero whatever the confidence score in the automated identification for $P$. pipistrellus 431 and $R$. ferrumequinum (Table 1), thus not raising any problem of error risk.

432 For all nine other species or species groups, 15 of the 18 significant responses to

433 environmental variables were robust with a high stability of model outputs while reducing the 434 FPT from 0.5 to 0.1 (Table 3). In addition, despite a decrease in bat activity measures due to 435 thresholding at FPTs, the occurrence of species remained highly stable whilst retaining 436 statistical power among FPTs. Our study thus demonstrates that using our approach many 437 ecological inferences could be robust against identification errors.

\section{Survey recommendations and limitations}

440 This study proposes a cautious method to account for identification errors in acoustic surveys

441 aimed at studying the response of bats in relation to environmental variables, such as

442 anthropogenic pressures, without the need for exhaustive checking of recordings.

443 The FPT of 0.5 is a threshold for which false negatives and false positives are expected to be 444 approximately balanced. However, false positives are more likely to produce biases because 445 their rate is strongly driven by the activity pattern of other species. In contrast, the FPT of 0.1 446 minimises the false positive rate, but at the cost of losing potentially a lot of data, so a high 447 generated false negative rate by discarding true positives (Table 2). Rather than looking for a 448 possible optimal threshold, we recommend that researchers systematically check the 449 consistency of responses for at least two significantly different thresholds (e.g. 0.5 and 0.1

450 FPTs), in order to assess the robustness of the results and only going on to conclusive 451 interpretation when these are consistent. 
452 A lack of consistency is most likely to occur for rare species with very low

453 abundance/occurrence, and for uncommon species which are acoustically similar to

454 commoner ones such as $P$. nathusii here which is acoustically similar to $P$. kuhlii (Obrist et

455 al., 2004). The efficiency of the automated identification of P. nathusii and N. lesleiri was

456 lowest (AUC of 0.73 for both; Fig. S3) due to particular context of the study where these

457 species were much rarer than their acoustically closest relative (P. kuhlii and E. serotinus,

458 respectively; Table 1). For these species, either systematic manual checking or an important

459 improvement in automated identification efficiency is needed to conduct robust analyses.

460 However, our framework of error rate modelling is already sufficient to effectively identify

461 these problematic species and should prevent users of automated identification to draw

462 conclusions that are not robust. In addition, another prerequisite for drawing robust

463 conclusions from this framework is to ensure that error types (i.e. false negatives and false

464 positives) are not correlated with the variables tested in the study. In our study case, we only

465 detected one significant dependence for the open area $v s$. hedgerows for the false positives of

$466 N$. noctula (Table S2). For this species, automated identification was more efficient (i.e. lower

467 number of false positives) for survey sites located in open areas than close to hedgerows

468 where calls are more difficult to identify due to frequency modulation (Obrist et al., 2004;

469 Barataud, 2015). It is not surprising that the false positive rate of a rare species like $N$. noctula

470 could be influenced by local habitat type because this variable is expected to have different

471 effects on other species, and thus influence false positive rate through the relative density

472 between $N$. noctula and other bat species. Thus, we expect a bias in the measure of activity

473 towards open areas in this case. Hence, the significant positive response of this species to

474 open areas compared to hedgerows should be considered unreliable to make any ecological

475 inference (Table 3). 
476 This method can be applied to any ecological studies with standardized sampling but, of

477 course, cannot help for surveys where no error can be tolerated, e.g. for producing species

478 inventories for protected species, as required for environmental impact assessments (Russo \&

479 Voigt 2016). However, in this case, automated identification can still indicate what bat passes

480 should be manually checked in order to identify species presence at the site scale, by selecting

481 passes with the highest confidence scores, and thus saving time for the user.

482 Finally, the proposed method can be applied to any acoustic taxa for which automated

483 identification software are developed and where confidence scores are provided. A crucial

484 advantage of this method is that manual checking of a relatively small subset of the dataset $(<$

$4851 \%$ in this study) is sufficient to assess error rates associated with species identification. This

486 is especially true given that checking all data is very time-consuming and virtually impossible

487 for such a large dataset. 
490 This work was supported by DIM ASTREA grants from Region Ile- de- France. We sincerely

491 thank Agrosolutions for funding field study fees. We thank IN2P3 Computing Centre for

492 providing facilities to process and archive in the long-term all the recordings of this study, and

493 Didier Bas for help in this process. We also thank the two anonymous reviewers for their

494 constructive comments improving this work.

495

496 Author's contribution

$497 \mathrm{~KB}, \mathrm{CK}$ and YB conceived the ideas, KB and YB designed the methodology, KB collected

498 the data; KB and YB manually checked bat passes, KB and JP analysed the data and wrote the

499 R scripts; all authors led the writing of the manuscript. All authors critically contributed to the

500 drafts and gave their final approval for publication.

501

502 Data accessibility

503 All R codes and data used in the study are available from the following github website link:

504 https://github.com/KevBarre/Semi-automated-method-to-account-for-identification-errors-in-

505 biological-acoustic-surveys. https://doi.org/10.5281/zenodo.2646482

506

507 


\section{References}

509 Adams, A. M., Jantzen, M. K., Hamilton, R. M., \& Fenton, M. B. (2012). Do you hear what I hear? Implications of detector selection for acoustic monitoring of bats. Methods in Ecology and Evolution, 3(6), 992-998. doi:10.1111/j.2041-210X.2012.00244.x

\section{2}

Azam, C., Le Viol, I., Bas, Y., Zissis, G., Vernet, A., Julien, J.-F., \& Kerbiriou, C. (2018). Evidence for distance and illuminance thresholds in the effects of artificial lighting on bat activity. Landscape and Urban Planning, (175), 123-135. doi:10.1016/j.landurbplan.2018.02.011

Azam, C., Le Viol, I., Julien, J. F., Bas, Y., \& Kerbiriou, C. (2016). Disentangling the relative effect of light pollution, impervious surfaces and intensive agriculture on bat activity with a national-scale monitoring program. Landscape Ecology, 31(10), 2471-2483. doi:10.1007/s10980-016-0417-3

Barataud, M. (2015). Acoustic ecology of european bats: species identification, study of their habitats and foraging behaviour (Biotope Ed).

Barré, K., Le Viol, I., Bas, Y., Julliard, R., \& Kerbiriou, C. (2018). Estimating habitat loss due to wind turbine avoidance by bats: Implications for European siting guidance. Biological Conservation, 226(April), 205-214. doi:10.1016/j.biocon.2018.07.011

Barré, K., Le Viol, I., Julliard, R., Chiron, F., \& Kerbiriou, C. (2017). Tillage and herbicide reduction mitigate the gap between conventional and organic farming effects on foraging activity of insectivorous bats. Ecology and Evolution, (00), 1-11. doi:10.1002/ece3.3688

Bas, Y., Bas, D., \& Julien, J. (2017). Tadarida : A Toolbox for Animal Detection on Acoustic Recordings. Journal of Open Research Software, 5(6), 1-8. doi:https://doi.org/10.5334/jors.154

Biotope. (2013). Manual of SonoChiro 3.0. Retrieved 24 April 2018, from http://www.leclubbiotope.com/index.php?controller=attachment\&id_attachment=13 
533 Boughey, K. L., Lake, I. R., Haysom, K. a., \& Dolman, P. M. (2011). Effects of landscapescale broadleaved woodland configuration and extent on roost location for six bat species across the UK. Biological Conservation, 144(9), 2300-2310. doi:10.1016/j.biocon.2011.06.008

Britzke, E. R., Duchamp, J. E., Murray, K. L., Swihart, R. K., \& Robbins, L. W. (2011). Acoustic identification of bats in the eastern United States: A comparison of parametric and nonparametric methods. Journal of Wildlife Management, 75(3), 660-667. doi:10.1002/jwmg.68

Butchart, S. H. M., Walpole, M., Collen, B., van Strien, A., Scharlemann, J. P. W., Almond, R. E. A., ... Watson, R. (2010). Global Biodiversity: Indicators of Recent Declines. Science, 328(5982), 1164-1168. doi:10.1126/science.1187512

Chatterjee, S., \& Hadi, A. S. (2006). Regression analysis by example (5th ed.). John Wiley \& Sons, Inc. doi:10.1002/0470055464

Claireau, F., Bas, Y., Puechmaille, S. J., Julien, J. F., Allegrini, B., \& Kerbiriou, C. (2018). Bat overpasses: An insufficient solution to restore habitat connectivity across roads. Journal of Applied Ecology, (September), 1-12. doi:10.1111/1365-2664.13288

Delport, W., Kemp, A. C., \& Ferguson, J. W. H. (2002). Vocal identification of individual African Wood Owls Strix woodfordii: A technique to monitor long-term adult turnover and residency. Ibis, 144(1), 30-39. doi:10.1046/j.0019-1019.2001.00019.x

Denzinger, A., \& Schnitzler, H. U. (2013). Bat guilds, a concept to classify the highly diverse foraging and echolocation behaviors of microchiropteran bats. Frontiers in Physiology, 4 JUL(July), 1-16. doi:10.3389/fphys.2013.00164

Fisher, J. A. D., Frank, K. T., \& Leggett, W. C. (2010). Dynamic macroecology on ecological time-scales. Global Ecology and Biogeography, 19(1), 1-15. doi:10.1111/j.14668238.2009.00482.x 
Frey-Ehrenbold, A., Bontadina, F., Arlettaz, R., \& Obrist, M. K. (2013). Landscape connectivity, habitat structure and activity of bat guilds in farmland-dominated matrices. Journal of Applied Ecology, 50(1), 252-261. doi:10.1111/1365-2664.12034

Fritsch, G., \& Bruckner, A. (2014). Operator bias in software-aided bat call identification. Ecology and Evolution, 4(13), 2703-2713. doi:10.1002/ece3.1122

Froidevaux, J. S. P., Zellweger, F., Bollmann, K., \& Obrist, M. K. (2014). Optimizing passive acoustic sampling of bats in forests. Ecology and Evolution, 4(24), 4690-4700. doi:10.1002/ece3.1296

Frommolt, K. H. (2017). Information obtained from long-term acoustic recordings: applying bioacoustic techniques for monitoring wetland birds during breeding season. Journal of Ornithology, 158(3), 659-668. doi:10.1007/s10336-016-1426-3

Gasc, A., Sueur, J., Pavoine, S., Pellens, R., \& Grandcolas, P. (2013). Biodiversity Sampling Using a Global Acoustic Approach: Contrasting Sites with Microendemics in New Caledonia. PLoS ONE, 8(5). doi:10.1371/journal.pone.0065311

Gibb, R., Browning, E., Glover-Kapfer, P., \& Jones, K. E. (2018). Emerging opportunities and challenges for passive acoustics in ecological assessment and monitoring. Methods in Ecology and Evolution, (October). doi:10.1111/2041-210X.13101

Jeliazkov, A., Bas, Y., Kerbiriou, C., Julien, J. F., Penone, C., \& Le Viol, I. (2016). Largescale semi-automated acoustic monitoring allows to detect temporal decline of bushcrickets. Global Ecology and Conservation, 6, 208-218. doi:10.1016/j.gecco.2016.02.008

Jung, K., \& Threlfall, C. (2016). Urbanization and its effect on bats: a global meta-analysis. In: Kingston T, Voigt C (eds) Bats in the anthropocene: conservation of bats in a changing world. (Springer, pp. 13-33).

Kalan, A. K., Mundry, R., Wagner, O. J. J., Heinicke, S., Boesch, C., \& Kühl, H. S. (2015). 

Towards the automated detection and occupancy estimation of primates using passive acoustic monitoring. Ecological Indicators, 54, 217-226. doi:10.1016/j.ecolind.2015.02.023

Kerbiriou, C., Azam, C., Touroult, J., Marmet, J., Julien, J. F., \& Pellissier, V. (2018). Common bats are more abundant within Natura 2000 areas. Biological Conservation, 217(October 2017), 66-74. doi:10.1016/j.biocon.2017.10.029

Kerbiriou, C., Bas, Y., Le Viol, I., Lorrilliere, R., Mougnot, J., \& Julien, J. F. (2018). Potential of bat pass duration measures for studies of bat activity. Bioacoustics, 4622, 116. doi:10.1080/09524622.2017.1423517

Lacoeuilhe, A., Machon, N., Julien, J. F., \& Kerbiriou, C. (2016). Effects of hedgerows on bats and bush crickets at different spatial scales. Acta Oecologica, 71, 61-72. doi:10.1016/j.actao.2016.01.009

López-Baucells, A., Torrent, L., Rocha, R., Bobrowiec, P. E. D., Palmeirim, J. M., \& Meyer, C. F. J. (2019). Stronger together: Combining automated classifiers with manual postvalidation optimizes the workload vs reliability trade-off of species identification in bat acoustic surveys. Ecological Informatics, 49, 45-53. doi:10.1016/j.ecoinf.2018.11.004

Mckinney, M. L. (2005). Urbanization as a major cause of biotic homogenization. Biological Conservation, 127(3), 247-260. doi:10.1016/j.biocon.2005.09.005

Millon, L., Julien, J.-F., Julliard, R., \& Kerbiriou, C. (2015). Bat activity in intensively farmed landscapes with wind turbines and offset measures. Ecological Engineering, 75, 250-257. doi:10.1016/j.ecoleng.2014.11.050

Newson, S. E., Evans, H. E., \& Gillings, S. (2015). A novel citizen science approach for large-scale standardised monitoring of bat activity and distribution, evaluated in eastern England. Biological Conservation, 191, 38-49. doi:10.1016/j.biocon.2015.06.009

Nowacek, D. P., Christiansen, F., Bejder, L., Goldbogen, J. A., \& Friedlaender, A. S. (2016). 
608

609

610

611

612

613

614

615

616

617

618

619

620

621

622

623

624

625

626

627

628

629

630

631

632

Studying cetacean behaviour: new technological approaches and conservation applications. Animal Behaviour, 120, 235-244. doi:10.1016/j.anbehav.2016.07.019

Obrist, M. K., Boesch, R., \& Fluckiger, P. F. (2004). Variability in echolocation call design of 26 Swiss bat species: consequences, limits and options for automated field identification with a synergetic pattern recognition approach. Mammalia, 68(4), 307-322. doi:10.1515/mamm.2004.030

Ovaskainen, O., Moliterno de Camargo, U., \& Somervuo, P. (2018). Animal Sound Identifier (ASI): software for automated identification of vocal animals. Ecology Letters, 21(8), 1244-1254. doi:10.1111/ele.13092

Parsons, S., \& Jones, G. (2000). Acoustic identification of twelve species of echolocating bat by discriminant function analysis and artificial neural networks. The Journal of Experimental Biology, 203(Pt 17), 2641-2656. doi:10.1007/s00114-005-0622-4

Pauwels, J., Viol, I. Le, Azam, C., Valet, N., Julien, J. -f., Bas, Y., ... Kerbiriou, C. (2019). Accounting for artificial light impact on bat activity for a biodiversity-friendly urban planning. Landscape and Urban Planning, 183(August 2018), 12-25. doi:S0169204618311939

Penone, C., Kerbiriou, C., Julien, J.-F., Marmet, J., \& Le Viol, I. (2018). Body size information in large-scale acoustic bat databases. PeerJ, 6, e5370. doi:10.7717/peerj.5370

Pinaud, D., Claireau, F., Leuchtmann, M., \& Kerbiriou, C. (2018). Modelling landscape connectivity for greater horseshoe bat using an empirical quantification of resistance. Journal of Applied Ecology, 55(6), 2600-2611. doi:10.1111/1365-2664.13228

Russo, D., \& Voigt, C. C. (2016). The use of automated identification of bat echolocation calls in acoustic monitoring: A cautionary note for a sound analysis. Ecological Indicators, 66, 598-602. doi:10.1016/j.ecolind.2016.02.036 
633 Rydell, J., Nyman, S., Eklöf, J., Jones, G., \& Russo, D. (2017). Testing the performances of 634 automated identification of bat echolocation calls: A request for prudence. Ecological $635 \quad$ Indicators, 78, 416-420. doi:10.1016/j.ecolind.2017.03.023

636 Santos, H., Rodrigues, L., Jones, G., \& Rebelo, H. (2013). Using species distribution 637 modelling to predict bat fatality risk at wind farms. Biological Conservation, 157, 178638 186. doi:10.1016/j.biocon.2012.06.017

639 Scott, C., \& Altringham, J. (2017). BatClassify. Retrieved 24 April 2018, from 640 https://bitbucket.org/chrisscott/batclassify

641 Sirami, C., Jacobs, D. S., \& Cumming, G. S. (2013). Artificial wetlands and surrounding 642 habitats provide important foraging habitat for bats in agricultural landscapes in the 643 Western Cape, South Africa. Biological Conservation, 164, 30-38. 644 doi:10.1016/j.biocon.2013.04.017

645 Stahlschmidt, P., \& Brühl, C. A. (2012). Bats as bioindicators - the need of a standardized 646 method for acoustic bat activity surveys. Methods in Ecology and Evolution, 3(3), 503647 508. doi:10.1111/j.2041-210X.2012.00188.x

648 Verboom, B., \& Huitema, H. (1997). The importance of linear landscape elements for the 649 pipistrelle Pipistrellus pipistrellus and the serotine bat Eptesicus serotinus. Landscape $650 \quad$ Ecology, 12(2), 117-125. doi:10.1007/BF02698211

651 Waters, D., \& Barlow, K. (2013). Bat detectors: past, present and future. British Wildlife, 87, 652 86-92.

653 Zuur, A. F., Ieno, E. N., Walker, N., Saveliev, A. A., \& Smith, G. M. (2009). Mixed effects 654 models and extensions in ecology with R. Springer Science \& Business Media. 655 doi:10.1007/978-0-387-87458-6 
658 Table 1. Total bat passes assigned to each species by the automated identification per

659 confidence score classes, number of bat passes manually double checked and false positives

660 noted (step 1 in Fig. 1). See Table S1 for species composition in false positives.

\begin{tabular}{|c|c|c|c|c|c|c|c|c|c|c|c|}
\hline \multirow{2}{*}{ Species } & \multicolumn{10}{|c|}{ Upper limits of confidence score classes of the automated identification } & \multirow[t]{2}{*}{ Total } \\
\hline & 0.1 & 0.2 & 0.3 & 0.4 & 0.5 & 0.6 & 0.7 & 0.8 & 0.9 & 1 & \\
\hline \multicolumn{12}{|l|}{ Barbastella barbastellus } \\
\hline Total passes & 3 & 52 & 144 & 242 & 297 & 671 & 940 & 1312 & 1596 & 578 & 5835 \\
\hline Checked passes & 3 & 25 & 25 & 25 & 25 & 25 & 25 & 25 & 25 & 25 & 228 \\
\hline False positives & 3 & 5 & 1 & 0 & 0 & 0 & 0 & 0 & 0 & 0 & $3.9 \%$ \\
\hline \multicolumn{12}{|l|}{ Eptesicus serotinus } \\
\hline Total passes & 1 & 55 & 102 & 149 & 268 & 461 & 218 & 79 & 10 & 0 & 1343 \\
\hline Checked passes & 1 & 25 & 25 & 25 & 25 & 25 & 25 & 25 & 9 & 0 & 185 \\
\hline False positives & 1 & 13 & 7 & 0 & 0 & 0 & 0 & 0 & 0 & 0 & $11.4 \%$ \\
\hline \multicolumn{12}{|l|}{ Myotis nattereri } \\
\hline Total passes & 9 & 166 & 211 & 223 & 225 & 411 & 269 & 180 & 247 & 47 & 1988 \\
\hline Checked passes & 9 & 9 & 3 & 6 & 8 & 2 & 2 & 10 & 23 & 25 & 97 \\
\hline False positives & 8 & 5 & 1 & 2 & 1 & 0 & 0 & 0 & 0 & 0 & $17.5 \%$ \\
\hline \multicolumn{12}{|l|}{ Myotis spp } \\
\hline $\begin{array}{r}\text { Iotal passes } \\
\text { Checked passes }\end{array}$ & 20 & 25 & $\begin{array}{l}815 \\
25\end{array}$ & 25 & 25 & $\begin{array}{c}1 / 08 \\
25\end{array}$ & $\begin{array}{c}1132 \\
25\end{array}$ & 25 & $\begin{array}{l}258 \\
25\end{array}$ & 25 & $\begin{array}{l}0430 \\
245\end{array}$ \\
\hline False positives & 19 & 14 & 6 & 6 & 4 & 0 & 0 & 0 & 0 & 0 & $20.0 \%$ \\
\hline \multicolumn{12}{|l|}{ Nyctalus leisleri } \\
\hline Total passes & 3 & 47 & 41 & 33 & 11 & 8 & 9 & 1 & 0 & 0 & 153 \\
\hline Checked passes & 3 & 25 & 25 & 25 & 11 & 8 & 9 & 1 & 0 & 0 & 107 \\
\hline False positives & 2 & 16 & 14 & 13 & 4 & 0 & 0 & 0 & 0 & 0 & $45.8 \%$ \\
\hline \multicolumn{12}{|l|}{ Nyctalus noctula } \\
\hline Total passes & 0 & 113 & 110 & 82 & 24 & 43 & 16 & 6 & 1 & 0 & 395 \\
\hline Checked passes & 0 & 25 & 25 & 25 & 24 & 25 & 16 & 6 & 1 & 0 & 147 \\
\hline False positives & 0 & 25 & 23 & 24 & 23 & 7 & 0 & 0 & 0 & 0 & $69.4 \%$ \\
\hline \multicolumn{12}{|l|}{ Pipistrellus kuhlii } \\
\hline Total passes & 12 & 223 & 401 & 667 & 1142 & 4026 & 6654 & 10222 & 5240 & 2 & 28589 \\
\hline Checked passes & 12 & 25 & 25 & 25 & 25 & 25 & 25 & 25 & 25 & 2 & 214 \\
\hline False positives & 11 & 10 & 8 & 4 & 2 & 2 & 1 & 0 & 0 & 0 & $17.8 \%$ \\
\hline \multicolumn{12}{|l|}{ Pipistrellus nathusii } \\
\hline Total passes & 0 & 12 & 33 & 37 & 93 & 183 & 153 & 61 & 5 & 0 & 577 \\
\hline Checked passes & 0 & 12 & 25 & 25 & 25 & 25 & 25 & 25 & 5 & 0 & 167 \\
\hline False positives & 0 & 11 & 20 & 20 & 19 & 17 & 15 & 9 & 1 & 0 & $67.1 \%$ \\
\hline \multicolumn{12}{|l|}{ Pipistrellus pipistrellus } \\
\hline Total passes & 2 & 303 & 760 & 1636 & 3298 & 8311 & 14221 & 27205 & 83744 & 28024 & 167504 \\
\hline Checked passes & 2 & 25 & 25 & 25 & 25 & 25 & 25 & 25 & 25 & 25 & 227 \\
\hline False positives & 1 & 2 & 0 & 1 & 1 & 0 & 0 & 1 & 0 & 0 & $2.6 \%$ \\
\hline \multicolumn{12}{|l|}{ Plecotus spp } \\
\hline Total passes & 8 & 139 & 176 & 194 & 174 & 250 & 206 & 145 & 56 & 4 & 1352 \\
\hline Checked passes & 8 & 30 & 26 & 25 & 28 & 25 & 25 & 25 & 25 & 4 & 221 \\
\hline False positives & 5 & 19 & 8 & 2 & 1 & 1 & 0 & 0 & 0 & 0 & $16.3 \%$ \\
\hline \multicolumn{12}{|l|}{ Rhinolophus ferrumequinum } \\
\hline Total passes & 0 & 0 & 0 & 0 & 1 & 6 & 5 & 28 & 1 & 0 & 41 \\
\hline Checked passes & 0 & 0 & 0 & 0 & 1 & 6 & 5 & 28 & 1 & 0 & 41 \\
\hline False positives & 0 & 0 & 0 & 0 & 0 & 0 & 0 & 0 & 0 & 0 & $0.0 \%$ \\
\hline \multicolumn{12}{|l|}{ Rhinolophus hipposideros } \\
\hline $\begin{array}{r}\text { Total passes } \\
\text { To }\end{array}$ & 0 & 1 & 1 & 10 & 8 & 16 & 26 & 62 & 4 & 0 & 128 \\
\hline Checked passes & 0 & 1 & 1 & 10 & 8 & 16 & 26 & 62 & 4 & 0 & 128 \\
\hline False positives & 0 & 1 & 1 & 7 & 1 & 0 & 0 & 0 & 0 & 0 & $7.8 \%$ \\
\hline
\end{tabular}


662 Table 2. Minimum confidence scores needed to ensure False Positive Tolerances (step 2 in

663 Fig. 1), associated changes in the number of bat passes, the occurrence (presence rate among

664 sites), the estimated false positive rate and the generated false negative rate estimated for the

665 whole dataset (212 347 bat passes; step 3 in Fig. 1).

\begin{tabular}{|c|c|c|c|c|c|c|}
\hline \multirow{2}{*}{ Species } & \multicolumn{6}{|c|}{ False Positive Tolerance } \\
\hline & Raw data & 0.5 & 0.4 & 0.3 & 0.2 & 0.1 \\
\hline \multicolumn{7}{|l|}{ Barbastella barbastellus } \\
\hline Confidence score & I & 0.119 & 0.133 & 0.148 & 0.167 & 0.195 \\
\hline No. of bat passes & 5835 & 5828 & 5824 & 5822 & 5809 & 5787 \\
\hline Occurrences & 0.694 & 0.694 & 0.694 & 0.694 & 0.694 & 0.694 \\
\hline Estimated false positive rate & 0.003 & 0.002 & 0.002 & 0.002 & 0.001 & 0.001 \\
\hline Estimated false negative rate & 0 & $<0.001$ & $<0.001$ & 0.001 & 0.003 & 0.006 \\
\hline \multicolumn{7}{|l|}{ Eptesicus serotinus } \\
\hline Confidence score & I & 0.180 & 0.200 & 0.221 & 0.246 & 0.285 \\
\hline No. of bat passes & 1343 & 1297 & 1287 & 1273 & 1255 & 1205 \\
\hline Occurrences & 0.373 & 0.339 & 0.336 & 0.333 & 0.324 & 0.312 \\
\hline Estimated false positive rate & 0.044 & 0.022 & 0.019 & 0.015 & 0.012 & 0.006 \\
\hline Estimated false negative rate & 0 & 0.011 & 0.016 & 0.023 & 0.031 & 0.065 \\
\hline \multicolumn{7}{|l|}{ Myotis nattereri } \\
\hline Confidence score & I & 0.229 & 0.271 & 0.317 & 0.373 & 0.458 \\
\hline No. of bat passes & 1986 & 1759 & 1659 & 1562 & 1436 & 1239 \\
\hline Occurrences & 0.688 & 0.648 & 0.624 & 0.609 & 0.578 & 0.529 \\
\hline Estimated false positive rate & 0.136 & 0.081 & 0.064 & 0.049 & 0.034 & 0.021 \\
\hline Estimated false negative rate & 0 & 0.036 & 0.059 & 0.087 & 0.132 & 0.199 \\
\hline \multicolumn{7}{|l|}{ Myotis spp. } \\
\hline Confidence score & I & 0.212 & 0.250 & 0.291 & 0.341 & 0.416 \\
\hline No. of bat passes & 6428 & 5783 & 5483 & 5135 & 4747 & 4173 \\
\hline Occurrences & 0.798 & 0.792 & 0.786 & 0.774 & 0.765 & 0.716 \\
\hline Estimated false positive rate & 0.145 & 0.092 & 0.073 & 0.054 & 0.038 & 0.024 \\
\hline Estimated false negative rate & 0 & 0.036 & 0.062 & 0.099 & 0.145 & 0.219 \\
\hline \multicolumn{7}{|l|}{ Nyctalus leisleri } \\
\hline Confidence score & I & 0.286 & 0.342 & 0.402 & 0.476 & 0.587 \\
\hline No. of bat passes & 153 & 67 & 43 & 28 & 22 & 12 \\
\hline Occurrences & 0.211 & 0.138 & 0.104 & 0.070 & 0.055 & 0.031 \\
\hline Estimated false positive rate & 0.502 & 0.305 & 0.222 & 0.149 & 0.115 & 0.075 \\
\hline \multirow{2}{*}{\multicolumn{7}{|c|}{ Nyctalus noctula }} \\
\hline & & & & & & \\
\hline Confidence score & 1 & 0.507 & 0.527 & 0.548 & 0.574 & 0.613 \\
\hline No. of bat passes & 395 & 61 & 50 & 41 & 29 & 22 \\
\hline Occurrences & 0.220 & 0.080 & 0.067 & 0.058 & 0.046 & 0.040 \\
\hline Estimated false positive rate & 0.850 & 0.212 & 0.158 & 0.120 & 0.066 & 0.042 \\
\hline Estimated false negative rate & 0 & 0.029 & 0.044 & 0.054 & 0.082 & 0.097 \\
\hline \multicolumn{7}{|l|}{ Pipistrellus kuhlii } \\
\hline Confidence score & I & 0.164 & 0.216 & 0.272 & 0.341 & 0.444 \\
\hline No. of bat passes & 28588 & 28456 & 28305 & 28077 & 27737 & 26854 \\
\hline Occurrences & 0.899 & 0.899 & 0.890 & 0.884 & 0.881 & 0.875 \\
\hline Estimated false positive rate & 0.033 & 0.030 & 0.028 & 0.026 & 0.023 & 0.019 \\
\hline Estimated false negative rate & 0 & 0.002 & 0.005 & 0.010 & 0.019 & 0.045 \\
\hline Pipistrellus nathusii & & & & & & \\
\hline Confidence score & l & 0.668 & 0.756 & 0.853 & 0.971 & I \\
\hline No. of bat passes & 577 & 101 & 18 & 0 & 0 & 0 \\
\hline Occurrences & 0.404 & 0.116 & 0.031 & 0.000 & 0.000 & 0.000 \\
\hline Estimated false positive rate & 0.623 & 0.437 & 0.370 & 1 & 1 & 1 \\
\hline Estimated false negative rate & 0 & 0.275 & 0.355 & 0.377 & I & I \\
\hline Pipistrellus pipistrellus & & & & & & \\
\hline Confidence score & I & 0.000 & 0.000 & 0.000 & 0.000 & 0.096 \\
\hline No. of bat passes & 167503 & 167503 & 167503 & 167503 & 167503 & 167502 \\
\hline Occurrences & 0.954 & 0.954 & 0.954 & 0.954 & 0.954 & 0.954 \\
\hline Estimated false positive rate & 0.007 & 0.007 & 0.007 & 0.007 & 0.007 & 0.007 \\
\hline Estimated false negative rate & 0.000 & 0.000 & 0.000 & 0.000 & 0.000 & 0.000 \\
\hline Plecotus spp. & & & & & & \\
\hline Confidence score & I & 0.184 & 0.217 & 0.253 & 0.298 & 0.364 \\
\hline No. of bat passes & 1352 & 1229 & 1185 & 1129 & 1034 & 909 \\
\hline Occurrences & 0.615 & 0.599 & 0.596 & 0.596 & 0.584 & 0.544 \\
\hline Estimated false positive rate & 0.128 & 0.079 & 0.065 & 0.051 & 0.034 & 0.019 \\
\hline Estimated false negative rate & 0 & 0.034 & 0.053 & 0.080 & 0.131 & 0.211 \\
\hline Rhinolophus ferrumequinum & & & & & & \\
\hline Confidence score & I & 0.000 & 0.000 & 0.000 & 0.000 & 0.000 \\
\hline No. of bat passes & 41 & 41 & 41 & 41 & 41 & 41 \\
\hline Occurrences & 0.046 & 0.046 & 0.046 & 0.046 & 0.046 & 0.046 \\
\hline Estimated false positive rate & 0.000 & 0.000 & 0.000 & 0.000 & 0.000 & 0.000 \\
\hline Estimated false negative rate & 0.000 & 0.000 & 0.000 & 0.000 & 0.000 & 0.000 \\
\hline Rhinolophus hipposideros & & & & & & \\
\hline Confidence score & l & 0.385 & 0.398 & 0.411 & 0.427 & 0.452 \\
\hline No. of bat passes & 128 & 117 & 116 & 116 & 116 & 113 \\
\hline Occurrences & 0.113 & 0.107 & 0.104 & 0.104 & 0.104 & 0.104 \\
\hline Estimated false positive rate & 0.078 & 0.011 & 0.007 & 0.007 & 0.007 & 0.003 \\
\hline Estimated false negative rate & 0 & 0.018 & 0.022 & 0.022 & 0.022 & 0.199 \\
\hline
\end{tabular}


667 Table 3. Species response to environmental variables (estimates, standard errors and p-values)

668 according to the False Positive Tolerances $(* * * \mathrm{P}<0.001, * * \mathrm{P}<0.01, * \mathrm{P}<0.05, . \mathrm{P}<0.1)$.

\begin{tabular}{|c|c|c|c|c|c|c|c|}
\hline \multirow{2}{*}{ Species } & \multirow{2}{*}{$\begin{array}{l}\text { Environmental } \\
\text { variables }\end{array}$} & \multicolumn{6}{|c|}{ False Positive Tolerance } \\
\hline & & Raw data & 0.5 & 0.4 & 0.3 & 0.2 & 0.1 \\
\hline $\begin{array}{l}\text { Barbastella } \\
\text { barbastellus }\end{array}$ & $\begin{array}{l}\text { Open areas vs. hedgerows } \\
\text { Dist. to forest } \\
\text { Dist. to wetland } \\
\text { Dist. to urban } \\
\text { Length of hedgerows }\end{array}$ & $\begin{array}{l}-2.81 \pm 0.24 \text { *** } \\
0.08 \pm 0.12 \\
-0.03 \pm 0.12 \\
0.01 \pm 0.1 \\
0.17 \pm 0.12\end{array}$ & $\begin{array}{l}-2.81 \pm 0.24 * * * \\
0.08 \pm 0.13 \\
-0.03 \pm 0.12 \\
0.01 \pm 0.1 \\
0.17 \pm 0.12\end{array}$ & $\begin{array}{l}-2.81 \pm 0.24 * * * \\
0.08 \pm 0.13 \\
-0.03 \pm 0.12 \\
0.01 \pm 0.1 \\
0.17 \pm 0.12\end{array}$ & $\begin{array}{l}-2.81 \pm 0.24 * * * \\
0.08 \pm 0.13 \\
-0.03 \pm 0.12 \\
0.01 \pm 0.1 \\
0.17 \pm 0.12\end{array}$ & $\begin{array}{l}-2.81 \pm 0.24 * * * \\
0.08 \pm 0.13 \\
-0.03 \pm 0.12 \\
0.01 \pm 0.1 \\
0.17 \pm 0.12\end{array}$ & $\begin{array}{l}-2.81 \pm 0.24 * * * \\
0.08 \pm 0.13 \\
-0.04 \pm 0.12 \\
0.02 \pm 0.1 \\
0.17 \pm 0.12\end{array}$ \\
\hline $\begin{array}{l}\text { Eptesicus } \\
\text { serotinus }\end{array}$ & $\begin{array}{l}\text { Open areas vs. hedgerows } \\
\text { Dist. to forest } \\
\text { Dist. to wetland } \\
\text { Dist. to urban } \\
\text { Length of hedgerows }\end{array}$ & $\begin{array}{l}-0.57 \pm 0.38 \\
-0.07 \pm 0.23 \\
0.08 \pm 0.19 \\
-0.7 \pm 0.19 \text { *** } \\
0.2 \pm 0.23\end{array}$ & $\begin{array}{l}-0.43 \pm 0.4 \\
-0.15 \pm 0.24 \\
0.12 \pm 0.2 \\
-0.8 \pm 0.21 * * * \\
0.2 \pm 0.24\end{array}$ & $\begin{array}{l}-0.44 \pm 0.4 \\
-0.15 \pm 0.25 \\
0.12 \pm 0.2 \\
-0.79 \pm 0.21 * * * \\
0.21 \pm 0.24\end{array}$ & $\begin{array}{l}-0.45 \pm 0.41 \\
-0.16 \pm 0.25 \\
0.12 \pm 0.2 \\
-0.78 \pm 0.21 \text { *** } \\
0.21 \pm 0.24\end{array}$ & $\begin{array}{l}-0.43 \pm 0.42 \\
-0.15 \pm 0.25 \\
0.12 \pm 0.21 \\
-0.77 \pm 0.21 \\
0.19 \pm 0.25\end{array}$ & $\begin{array}{l}-0.35 \pm 0.42 \\
-0.13 \pm 0.26 \\
0.08 \pm 0.21 \\
-0.77 \pm 0.22 * * * \\
0.16 \pm 0.25\end{array}$ \\
\hline $\begin{array}{l}\text { Myotis } \\
\text { nattereri }\end{array}$ & $\begin{array}{l}\text { Open areas vs. hedgerows } \\
\text { Dist. to forest } \\
\text { Dist. to wetland } \\
\text { Dist. to urban } \\
\text { Length of hedgerows }\end{array}$ & $\begin{array}{l}-1.16 \pm 0.21 * * * \\
0.16 \pm 0.13 \\
0.17 \pm 0.11 \\
0.07 \pm 0.1 \\
0.18 \pm 0.12\end{array}$ & $\begin{array}{l}-1.14 \pm 0.22 * * * \\
0.13 \pm 0.13 \\
0.21 \pm 0.12 \\
0.08 \pm 0.11 \\
0.22 \pm 0.13\end{array}$ & $\begin{array}{l}-1.12 \pm 0.23 * * * \\
0.14 \pm 0.13 \\
0.23 \pm 0.12 \\
0.09 \pm 0.11 \\
0.24 \pm 0.13\end{array}$ & $\begin{array}{l}-1.05 \pm 0.23 * * * \\
0.15 \pm 0.14 \\
0.24 \pm 0.12 \\
0.11 \pm 0.12 \\
0.27 \pm 0.14\end{array}$ & $\begin{array}{l}-1.01 \pm 0.24 * * * \\
0.1 \pm 0.14 \\
0.22 \pm 0.13 \\
0.11 \pm 0.12 \\
0.32 \pm 0.14 *\end{array}$ & $\begin{array}{l}-1.03 \pm 0.27 * * * \\
0.11 \pm 0.15 \\
0.21 \pm 0.13 \\
0.13 \pm 0.13 \\
0.3 \pm 0.16\end{array}$ \\
\hline Myotis spp & $\begin{array}{l}\text { Open areas vs. hedgerows } \\
\text { Dist. to forest } \\
\text { Dist. to wetland } \\
\text { Dist. to urban } \\
\text { Length of hedgerows }\end{array}$ & $\begin{array}{l}-1.66 \pm 0.19 * * * \\
0.24 \pm 0.12 * \\
0.1 \pm 0.1 \\
-0.07 \pm 0.09 \\
0.13 \pm 0.12\end{array}$ & $\begin{array}{l}-1.64 \pm 0.19 * * * \\
0.22 \pm 0.12 \\
0.11 \pm 0.11 \\
-0.08 \pm 0.09 \\
0.15 \pm 0.12\end{array}$ & $\begin{array}{l}-1.6 \pm 0.19 * * * \\
0.22 \pm 0.12 \\
0.1 \pm 0.11 \\
-0.08 \pm 0.1 \\
0.15 \pm 0.12\end{array}$ & $\begin{array}{l}-1.55 \pm 0.19 \text { *** } \\
0.22 \pm 0.12 \\
0.11 \pm 0.11 \\
-0.06 \pm 0.1 \\
0.17 \pm 0.12\end{array}$ & $\begin{array}{l}-1.54 \pm 0.19 * * * \\
0.22 \pm 0.13 \\
0.1 \pm 0.11 \\
-0.05 \pm 0.1 \\
0.18 \pm 0.12\end{array}$ & $\begin{array}{l}-1.61 \pm 0.26 * * * \\
0.20 \pm 0.13 \\
0.10 \pm 0.11 \\
-0.03 \pm 0.1 \\
0.21 \pm 0.13\end{array}$ \\
\hline $\begin{array}{l}\text { Nyctalus } \\
\text { leisleri }\end{array}$ & $\begin{array}{l}\text { Open areas vs. hedgerows } \\
\text { Dist. to forest } \\
\text { Dist. to wetland } \\
\text { Dist. to urban } \\
\text { Length of hedgerows }\end{array}$ & $\begin{array}{l}-0.8 \pm 0.22 * * * \\
0.34 \pm 0.13 * * \\
0.07 \pm 0.1 \\
-0.1 \pm 0.1 \\
0.35 \pm 0.12 * *\end{array}$ & $\begin{array}{l}-0.26 \pm 0.29 \\
0.16 \pm 0.17 \\
-0.09 \pm 0.15 \\
-0.19 \pm 0.15 \\
0.23 \pm 0.16\end{array}$ & $\begin{array}{l}-0.23 \pm 0.35 \\
0.21 \pm 0.21 \\
-0.02 \pm 0.19 \\
-0.01 \pm 0.18 \\
0.23 \pm 0.21\end{array}$ & $\begin{array}{l}0.43 \pm 0.4 \\
0.08 \pm 0.26 \\
-0.12 \pm 0.26 \\
0.08 \pm 0.23 \\
0.27 \pm 0.25\end{array}$ & $\begin{array}{l}0.69 \pm 0.45 \\
0.14 \pm 0.28 \\
-0.21 \pm 0.3 \\
0.23 \pm 0.26 \\
0.28 \pm 0.29\end{array}$ & $\begin{array}{l}1.1 \pm 0.64 \\
0.49 \pm 0.35 \\
-0.17 \pm 0.42 \\
0.43 \pm 0.35 \\
0.22 \pm 0.41\end{array}$ \\
\hline $\begin{array}{l}\text { Nyctalus } \\
\text { noctula }\end{array}$ & $\begin{array}{l}\text { Open areas vs. hedgerows } \\
\text { Dist. to forest } \\
\text { Dist. to wetland } \\
\text { Dist. to urban } \\
\text { Length of hedgerows }\end{array}$ & $\begin{array}{l}-1.19 \pm 0.17 * * * \\
-0.55 \pm 0.11 * * * \\
-0.07 \pm 0.06 \\
0.25 \pm 0.07 * * * \\
0.34 \pm 0.08 * * *\end{array}$ & $\begin{array}{l}1.46 \pm 0.31 * * * \\
-0.68 \pm 0.23 * * \\
0.02 \pm 0.18 \\
-0.07 \pm 0.18 \\
0.43 \pm 0.21 *\end{array}$ & $\begin{array}{l}1.7 \pm 0.36 * * * \\
-0.66 \pm 0.26 * \\
0.16 \pm 0.21 \\
-0.1 \pm 0.21 \\
0.49 \pm 0.25 *\end{array}$ & $\begin{array}{l}1.83 \pm 0.4 * * * \\
-0.7 \pm 0.29 * \\
0.25 \pm 0.24 \\
-0.12 \pm 0.23 \\
0.52 \pm 0.28\end{array}$ & $\begin{array}{l}1.37 \pm 0.44 * * \\
-0.26 \pm 0.32 \\
0.3 \pm 0.27 \\
-0.01 \pm 0.25 \\
0.16 \pm 0.31\end{array}$ & $\begin{array}{l}1.28 \pm 0.49 * \\
-0.12 \pm 0.35 \\
0.34 \pm 0.34 \\
-0.04 \pm 0.29 \\
-0.03 \pm 0.36\end{array}$ \\
\hline $\begin{array}{l}\text { Pipistrellus } \\
\text { kuhlii }\end{array}$ & $\begin{array}{l}\text { Open areas vs. Hedgerows } \\
\text { Dist. to forest } \\
\text { Dist. to wetland } \\
\text { Dist. to urban } \\
\text { Length of hedgerows }\end{array}$ & $\begin{array}{l}-1.98 \pm 0.26 * * * \\
0.09 \pm 0.13 \\
0.25 \pm 0.13 * \\
0.07 \pm 0.13 \\
0.07 \pm 0.15\end{array}$ & $\begin{array}{l}-1.98 \pm 0.26 * * * \\
0.09 \pm 0.13 \\
0.25 \pm 0.13 * \\
0.07 \pm 0.13 \\
0.06 \pm 0.15\end{array}$ & $\begin{array}{l}-1.98 \pm 0.27 * * * \\
0.09 \pm 0.13 \\
0.26 \pm 0.13 * \\
0.07 \pm 0.13 \\
0.06 \pm 0.15\end{array}$ & $\begin{array}{l}-1.98 \pm 0.27 \text { *** } \\
0.09 \pm 0.14 \\
0.25 \pm 0.13 * \\
0.08 \pm 0.13 \\
0.06 \pm 0.15\end{array}$ & $\begin{array}{l}-1.98 \pm 0.27 \text { *** } \\
0.09 \pm 0.14 \\
0.26 \pm 0.13^{*} \\
0.08 \pm 0.13 \\
0.06 \pm 0.15\end{array}$ & $\begin{array}{l}-1.98 \pm 0.27 * * * \\
0.1 \pm 0.14 \\
0.26 \pm 0.13 * \\
0.08 \pm 0.13 \\
0.06 \pm 0.15\end{array}$ \\
\hline $\begin{array}{l}\text { Pipistrellus } \\
\text { nathusii }\end{array}$ & $\begin{array}{l}\text { Open areas vs. Hedgerows } \\
\text { Dist. to forest } \\
\text { Dist. to wetland } \\
\text { Dist. to urban } \\
\text { Length of hedgerows }\end{array}$ & $\begin{array}{l}-0.37 \pm 0.24 \\
0.1 \pm 0.16 \\
0.06 \pm 0.13 \\
-0.05 \pm 0.13 \\
0.11 \pm 0.16\end{array}$ & $\begin{array}{l}1.02 \pm 0.38 * * \\
0.28 \pm 0.23 \\
0.02 \pm 0.2 \\
0.09 \pm 0.21 \\
0.42 \pm 0.24\end{array}$ & $\begin{array}{l}2.57 \pm 0.84 * * \\
0.81 \pm 0.46 \\
0.53 \pm 0.42 \\
0 \pm 0.44 \\
0.88 \pm 0.54\end{array}$ & $\begin{array}{l}1 \\
1 \\
1 \\
1 \\
1\end{array}$ & $\begin{array}{l}1 \\
1 \\
1 \\
1 \\
1\end{array}$ & $\begin{array}{l}1 \\
1 \\
1 \\
1 \\
1\end{array}$ \\
\hline $\begin{array}{l}\text { Pipistrellus } \\
\text { pipistrellus }\end{array}$ & $\begin{array}{l}\text { Open areas vs. Hedgerows } \\
\text { Dist. to forest } \\
\text { Dist. to wetland } \\
\text { Dist. to urban } \\
\text { Length of hedgerows }\end{array}$ & $\begin{array}{l}-2.87 \pm 0.19 \text { *** } \\
0.13 \pm 0.13 \\
0.04 \pm 0.11 \\
-0.13 \pm 0.1 \\
0.35 \pm 0.12 * *\end{array}$ & $\begin{array}{l}-2.87 \pm 0.19 * * * \\
0.13 \pm 0.13 \\
0.04 \pm 0.11 \\
-0.13 \pm 0.1 \\
0.35 \pm 0.12 * *\end{array}$ & $\begin{array}{l}-2.87 \pm 0.19 * * * \\
0.13 \pm 0.13 \\
0.04 \pm 0.11 \\
-0.13 \pm 0.1 \\
0.35 \pm 0.12 * *\end{array}$ & $\begin{array}{l}-2.87 \pm 0.19 * * * \\
0.13 \pm 0.13 \\
0.04 \pm 0.11 \\
-0.13 \pm 0.1 \\
0.35 \pm 0.12 * *\end{array}$ & $\begin{array}{l}-2.87 \pm 0.19 \text { *** } \\
0.13 \pm 0.13 \\
0.04 \pm 0.11 \\
-0.13 \pm 0.1 \\
0.35 \pm 0.12 * *\end{array}$ & $\begin{array}{l}-2.87 \pm 0.19 * * * \\
0.13 \pm 0.13 \\
0.04 \pm 0.11 \\
-0.13 \pm 0.1 \\
0.35 \pm 0.12 * *\end{array}$ \\
\hline Plecotus spp. & $\begin{array}{l}\text { Open areas vs. Hedgerows } \\
\text { Dist. to forest } \\
\text { Dist. to wetland } \\
\text { Dist. to urban } \\
\text { Length of hedgerows }\end{array}$ & $\begin{array}{l}-0.91 \pm 0.19 * * * \\
0.08 \pm 0.12 \\
-0.16 \pm 0.11 \\
-0.25 \pm 0.1 * * \\
0.1 \pm 0.12\end{array}$ & $\begin{array}{l}-0.85 \pm 0.19 * * * \\
0.1 \pm 0.12 \\
-0.14 \pm 0.11 \\
-0.25 \pm 0.1 * \\
0.09 \pm 0.12\end{array}$ & $\begin{array}{l}-0.87 \pm 0.19 * * * \\
0.11 \pm 0.12 \\
-0.15 \pm 0.11 \\
-0.26 \pm 0.1 * * \\
0.09 \pm 0.12\end{array}$ & $\begin{array}{l}-0.87 \pm 0.19 * * * \\
0.1 \pm 0.12 \\
-0.15 \pm 0.11 \\
-0.25 \pm 0.1 * * \\
0.08 \pm 0.12\end{array}$ & $\begin{array}{l}-0.85 \pm 0.19 * * * \\
0.09 \pm 0.12 \\
-0.14 \pm 0.11 \\
-0.25 \pm 0.1 * \\
0.11 \pm 0.12\end{array}$ & $\begin{array}{l}-0.79 \pm 0.2 * * * \\
0.08 \pm 0.13 \\
-0.17 \pm 0.12 \\
-0.23 \pm 0.1 * \\
0.11 \pm 0.13\end{array}$ \\
\hline $\begin{array}{l}\text { Rhinolophus } \\
\text { ferrumequinum }\end{array}$ & $\begin{array}{l}\text { Open areas vs. Hedgerows } \\
\text { Dist. to forest } \\
\text { Dist. to wetland } \\
\text { Dist. to urban } \\
\text { Length of hedgerows }\end{array}$ & $\begin{array}{l}0.26 \pm 0.39 \\
0.74 \pm 0.25 * * \\
-1.2 \pm 0.29 * * * \\
-0.21 \pm 0.26 \\
0.83 \pm 0.29 * *\end{array}$ & $\begin{array}{l}0.26 \pm 0.39 \\
0.74 \pm 0.25 * * \\
-1.20 \pm 0.29 * * * \\
-0.21 \pm 0.26 \\
0.83 \pm 0.29 * *\end{array}$ & $\begin{array}{l}0.26 \pm 0.39 \\
0.74 \pm 0.25 * * \\
-1.20 \pm 0.29 * * * \\
-0.21 \pm 0.26 \\
0.83 \pm 0.29 * *\end{array}$ & $\begin{array}{l}0.26 \pm 0.39 \\
0.74 \pm 0.25 * * \\
-1.20 \pm 0.29 * * * \\
-0.21 \pm 0.26 \\
0.83 \pm 0.29 * *\end{array}$ & $\begin{array}{l}0.26 \pm 0.39 \\
0.74 \pm 0.25 * * \\
-1.20 \pm 0.29 * * * \\
-0.21 \pm 0.26 \\
0.83 \pm 0.29 * *\end{array}$ & $\begin{array}{l}0.26 \pm 0.39 \\
0.74 \pm 0.25 * * \\
-1.20 \pm 0.29 * * * \\
-0.21 \pm 0.26 \\
0.83 \pm 0.29 * *\end{array}$ \\
\hline $\begin{array}{l}\text { Rhinolophus } \\
\text { hipposideros }\end{array}$ & $\begin{array}{l}\text { Open areas vs. Hedgerows } \\
\text { Dist. to forest } \\
\text { Dist. to wetland } \\
\text { Dist. to urban } \\
\text { Length of hedgerows }\end{array}$ & $\begin{array}{l}-3.08 \pm 0.74 * * * \\
0.09 \pm 0.3 \\
-0.33 \pm 0.26 \\
-0.18 \pm 0.26 \\
0.03 \pm 0.3\end{array}$ & $\begin{array}{l}-2.92 \pm 0.73 * * * \\
-0.47 \pm 0.36 \\
-0.45 \pm 0.26 \\
-0.17 \pm 0.26 \\
0.06 \pm 0.3\end{array}$ & $\begin{array}{l}-2.92 \pm 0.74 * * * \\
-0.5 \pm 0.37 \\
-0.49 \pm 0.27 \\
-0.14 \pm 0.27 \\
0.07 \pm 0.3\end{array}$ & $\begin{array}{l}-2.92 \pm 0.74 \text { *** } \\
-0.5 \pm 0.37 \\
-0.49 \pm 0.27 \\
-0.14 \pm 0.27 \\
0.07 \pm 0.3\end{array}$ & $\begin{array}{l}-2.92 \pm 0.74 * * * \\
-0.5 \pm 0.37 \\
-0.49 \pm 0.27 \\
-0.14 \pm 0.27 \\
0.07 \pm 0.3\end{array}$ & $\begin{array}{l}-2.89 \pm 0.73 * * * \\
-0.51 \pm 0.36 \\
-0.46 \pm 0.28 \\
-0.15 \pm 0.27 \\
0.08 \pm 0.3\end{array}$ \\
\hline
\end{tabular}


670 Fig. 1. Schematic and chronological representation of the steps used to study the relationship

671 between automated identification errors in acoustic data and the detected relationship between

672 bat activity and environmental variables.

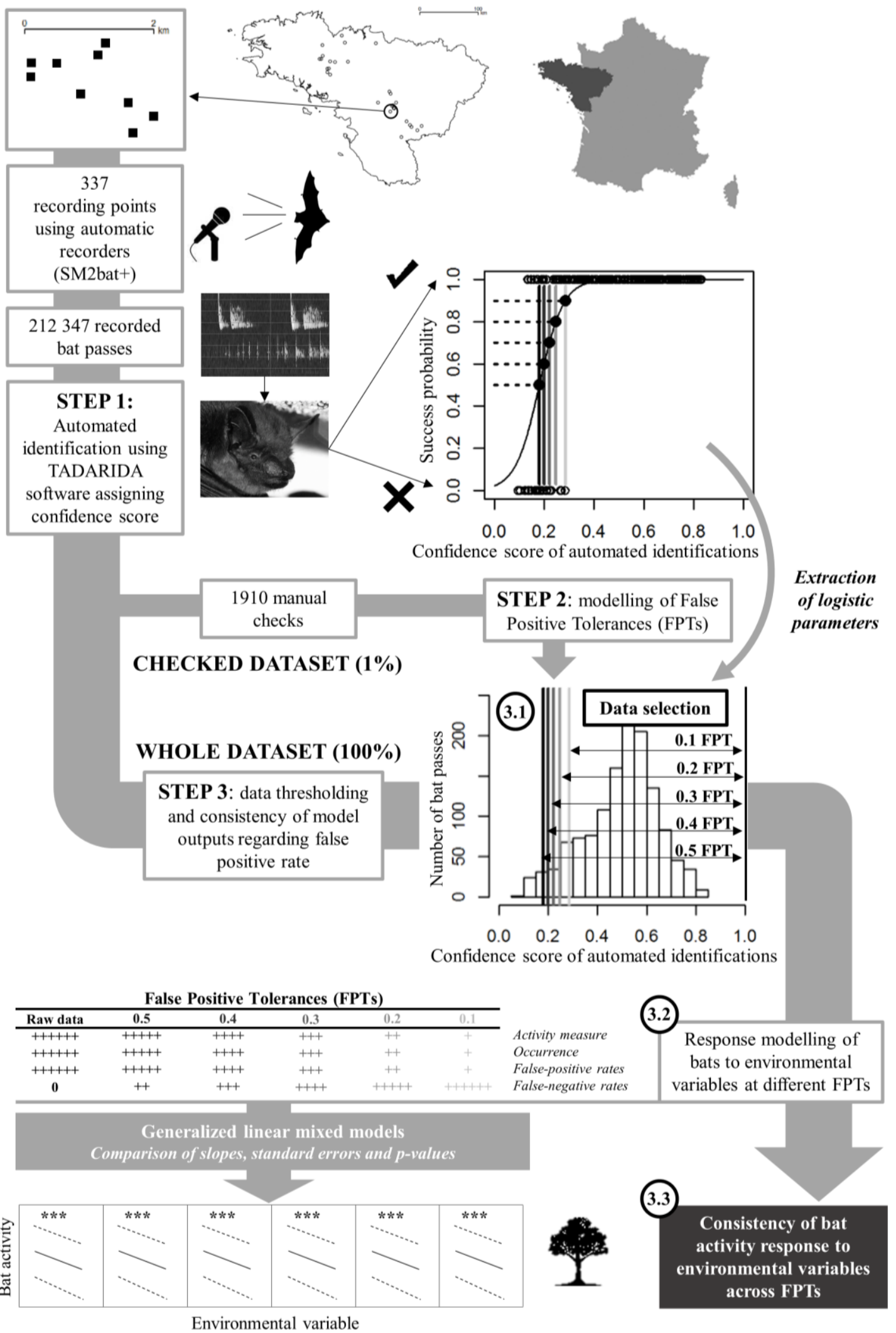


674 Fig. 2. Logistic regressions between the success probability and the confidence score of the

675 automated identification. The success probability was predicted from a subset manually

676 checked assigning a success or a failure in automated identifications. Horizontal dotted lines

677 show success probabilities in automated identification used for thresholding (i.e. False

678 Positive Tolerances: 0.5, 0.4, 0.3, 0.2 and 0.1 ) to remove data in the total dataset below the

679 corresponding confidence scores (vertical lines).
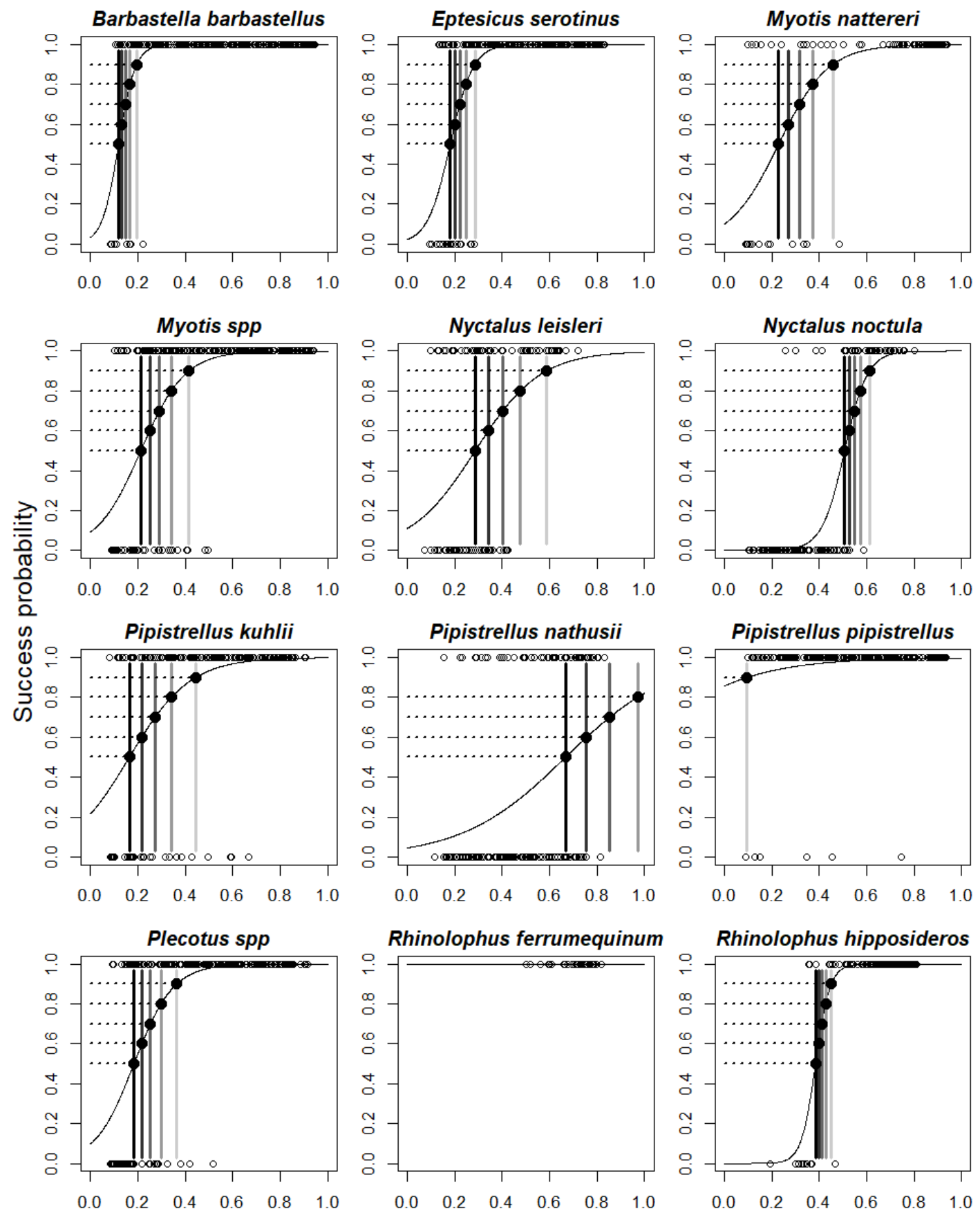
681 Fig. 3. Number of bat passes in the total dataset according to confidence scores provided by

682 the automated identification. Vertical lines show the threshold below which data were

683 removed to ensure a given False Positive Tolerance (from black to grey: 0.5, 0.4, 0.3, 0.2 and $6840.1)$
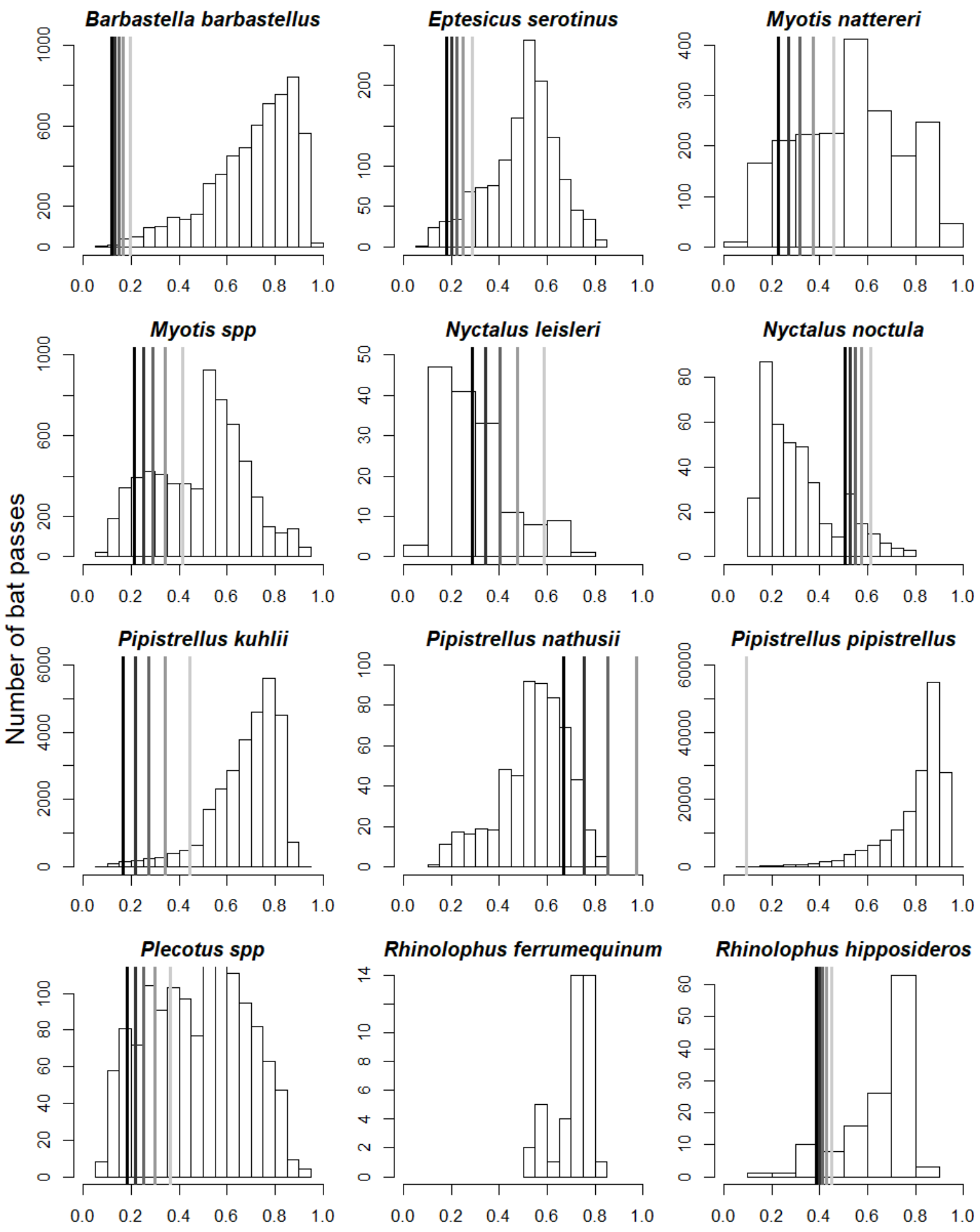